Proceedings of the International Symposium on Physics of Materials (ISPMA 14), September 10-15, 2017, Prague

\title{
Hot Deformation Behavior of $\boldsymbol{\beta}$-Solidifying TiAl Based Alloy
}

\author{
V.S. Sokolovsky ${ }^{a, *}$, N.D. Stepanov ${ }^{a}$, S.V. Zherebtsov ${ }^{a}$, N.A. Nochovnaya ${ }^{b}$ \\ P.V. PANIN ${ }^{b}$ AND G.A. SAlishCHEV ${ }^{a}$ \\ ${ }^{a}$ Belgorod State University, 85 Pobeda Str., 308015, Belgorod, Russian Federation \\ ${ }^{b}$ Federal State Unitary Enterprise "All-Russian Scientific Research Institute of Aviation Materials", \\ 17 Radio Str., 105005, Moscow, Russian Federation
}

\begin{abstract}
High-temperature mechanical behavior and microstructure evolution during hot deformation of an as-cast $\beta$-solidified Ti-44Al-2V-1Nb-1Zr-0.2Gd-0.2B alloy were studied. The as-cast alloy was subjected to uniaxial compression at temperatures from 1100 to $1250^{\circ} \mathrm{C}$ and strain rates in the range $0.001-1 \mathrm{~s}^{-1}$. Different mechanisms of microstructure evolution were found to operate depending on deformation temperature and phase fields. Transformation of the initial lamellar microstructure into globular one in the $\alpha_{2}+\gamma$ and $\alpha+\gamma$ phase fields were associated with dynamic recrystallization/spheroidization processes. Dynamic recrystallization was the controlling process of the microstructure evolution in the $\alpha$ and $\alpha+\beta$ phase fields. Deformation in all phase fields resulted in microstructure refinement which, in turn, induced superplasticity under certain temperature-strain rate conditions. The relationships between mechanical behavior and microstructure after deformation were discussed.
\end{abstract}

DOI: 10.12693/APhysPolA.134.675

PACS/topics: 81.40.Lm, 81.40.Gh, 87.15.La

\section{Introduction}

Intermetallic $\gamma$-TiAl based alloys are considered as promising materials for aerospace and automotive industries, and potentially can be used for manufacturing of gas turbine blades, turbine rotor discs, and automobile valves due to low density and good high temperature performance $[1,2]$. However, $\gamma$-TiAl alloys have found only limited applications because of low ductility at room temperature [1]. Several approaches to improve the low-temperature ductility while maintaining a sufficient level of high-temperature mechanical properties have been suggested so far [1]. One of the ways is to decrease the size of lamellae colonies, for example, by hot working [3]. However, poor ductility makes any thermomechanical processing of $\gamma$-TiAl alloys quite complicated.

In the present study deformation behavior and microstructure evolution of a $\beta$-solidifying $\gamma$-TiAl based alloy with a nominal composition $\mathrm{Ti}-44 \mathrm{Al}-2 \mathrm{~V}-1 \mathrm{Nb}-1 \mathrm{Zr}-$ $0.2 \mathrm{Gd}-0.2 \mathrm{~B}$ were studied in the temperature range of 1100 to $1250^{\circ} \mathrm{C}$ and the strain rate range $0.001-1 \mathrm{~s}^{-1}$. The effect of rare earth element (REE) on the initial microstructure, its evolution during deformation and mechanical behavior of $\beta$-solidifying alloys has not been investigated so far.

\section{Materials and procedure}

A $\gamma$-TiAl based alloy with a nominal composition of $\mathrm{Ti}-44 \mathrm{Al}-2 \mathrm{~V}-1 \mathrm{Nb}-1 \mathrm{Zr}-0.2 \mathrm{Gd}-0.2 \mathrm{~B}$ (at.\%) was produced by chill casting. Cylindrical specimens having $10 \mathrm{~mm}$ in diameter and $15 \mathrm{~mm}$ in height were compressed isothermally to a true strain of 1.2 at constant strain rates of

*corresponding author; e-mail: sokolovskiy@bsu.edu.ru
$0.001,0.01,0.1$, and $1.0 \mathrm{~s}^{-1}$ and temperatures of 1100 , 1150,1200 , and $1250^{\circ} \mathrm{C}$. After straining, the specimens were quenched by argon gas flow. The deformed specimens were sectioned along the compression axis. The microstructure of the compressed specimens was examined in central area.

The microstructure was examined using scanning electron microscopy (SEM), electron backscattered diffraction (EBSD), and transmission electron microscopy (TEM).

\section{Results and discussion}

The microstructure of the as-cast $\mathrm{Ti}-44 \mathrm{Al}-2 \mathrm{~V}-1 \mathrm{Nb}-$ $1 \mathrm{Zr}-0.2 \mathrm{Gd}-0.2 \mathrm{~B}$ was found to consist mainly of $\alpha_{2}+$ $\gamma$ lamellae colonies surrounded by particles of various chemical compositions (the $\gamma$ phase, the $\beta$ phase, two types of Gd-rich phases and two types of borides, Fig. 1). The size of the $\alpha_{2}+\gamma$ colonies was approximately $20 \mu \mathrm{m}$ (Fig. 1) with the average inter-lamellar spacing of $70 \mathrm{~nm}$.

Stress-strain curves of the Ti-44Al-2V-1Nb-1Zr$0.2 \mathrm{Gd}-0.2 \mathrm{~B}$ alloy obtained during isothermal compression at $1100-1250^{\circ} \mathrm{C}$ showed stress peak at the beginning of plastic flow followed by a flow softening and a steady state flow stage (Fig. 2) that is quite typical of high temperature deformation of such kind of materials. The flow stress of the alloy expectably decreased with increase of temperature and decrease of strain rate. In addition, the length of the steady state flow stages became greater in those phase fields which corresponded to higher temperatures. At low temperatures and high strain rates some specimens fractured before attaining the target deformation $\varphi=1.2$ (Fig. 2). Flow stress oscillations, which were observed at temperatures $\geq 1150^{\circ} \mathrm{C}$ and a high strain rate (Fig. 2), can be associated with dynamic recrystallization. 


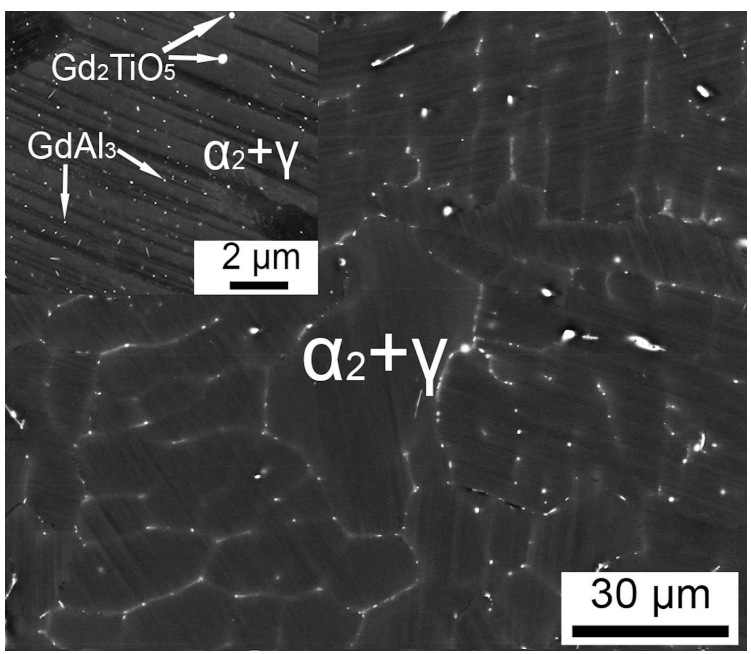

Fig. 1. Microstructure of the as-cast $\mathrm{Ti}-44 \mathrm{Al}-2 \mathrm{~V}-$ $1 \mathrm{Nb}-1 \mathrm{Zr}-0.2 \mathrm{Gd}-0.2 \mathrm{~B}$ alloy.
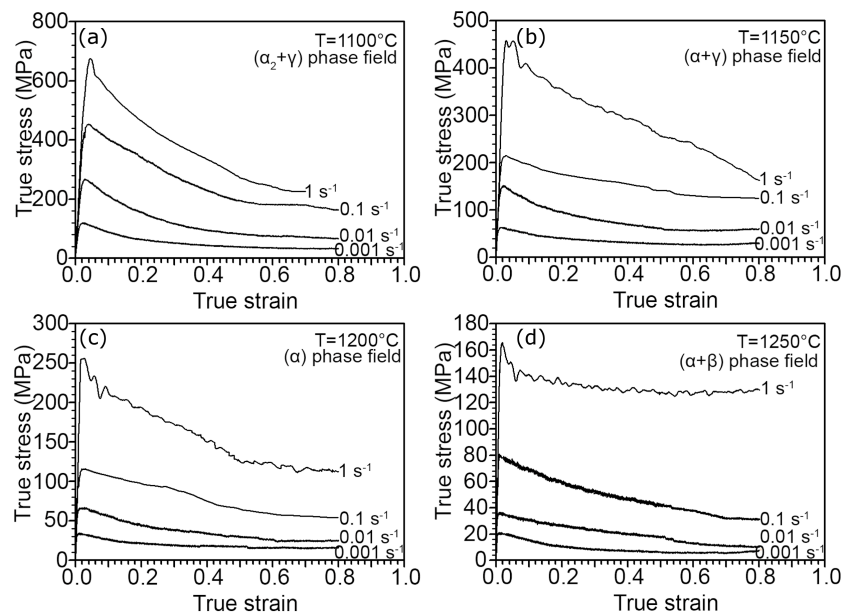

Fig. 2. True stress-true strain curves: $T=1100^{\circ} \mathrm{C}$ (a), $T=1150{ }^{\circ} \mathrm{C}(\mathrm{b}), T=1200^{\circ} \mathrm{C}(\mathrm{c}), T=1250{ }^{\circ} \mathrm{C}(\mathrm{d})$.

Microstructure of the alloy compressed to $\varphi=$ 1.2 depended considerably on deformation temperature (Fig. 3). Deformation at the temperature $1100{ }^{\circ} \mathrm{C}(\alpha 2+\gamma$ phase field) (Fig. 3a) resulted in transformation of the initial $\alpha 2+\gamma$ lamellae microstructure into equiaxed $\alpha 2$ and $\gamma$ phase particles $[4-6]$. The lamellae transformation occurred due to the development of a recrystallization/spheroidization processes. The fraction and the size of the spheroidized/recrystallized grains increased with an increase of deformation temperature and decrease of strain rate (Figs. 4, 5).

Homogeneous fine-grained structure formed at $1100^{\circ} \mathrm{C}$ and $0.001 \mathrm{~s}^{-1}$ (Fig. 3a). During deformation in the $\alpha+\gamma$ phase field $\left(1150^{\circ} \mathrm{C}\right)$ mainly lamellar was transformed into equiaxed one. An increase in deformation temperature from $1200^{\circ} \mathrm{C}$ to $1250{ }^{\circ} \mathrm{C}$ resulted in microstructure coarsening (Fig. 3c,d).

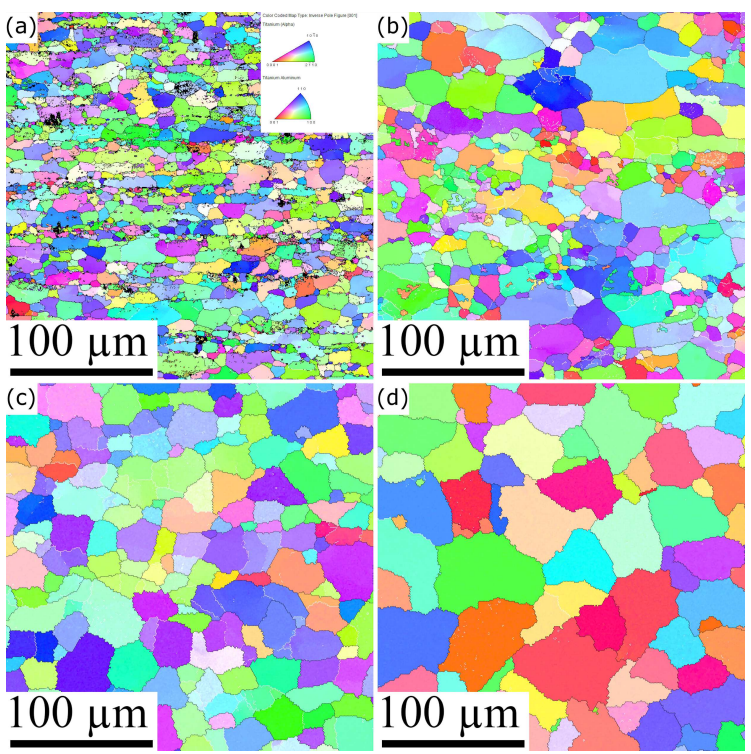

Fig. 3. EBSD inverse-pole-figure (IPF) of the Ti$44 \mathrm{Al}-2 \mathrm{~V}-1 \mathrm{Nb}-1 \mathrm{Zr}-0.2 \mathrm{Gd}-0.2 \mathrm{~B}$ alloy after uniaxial compression at $1100^{\circ} \mathrm{C}$ (a), $1150{ }^{\circ} \mathrm{C}$ (b), $1200^{\circ} \mathrm{C}$ (c), and $1250^{\circ} \mathrm{C}(\mathrm{d})$ and strain rates of $0.001 \mathrm{~s}^{-1}$ to a strain of $\varphi=1.2$. The loading direction is vertical.

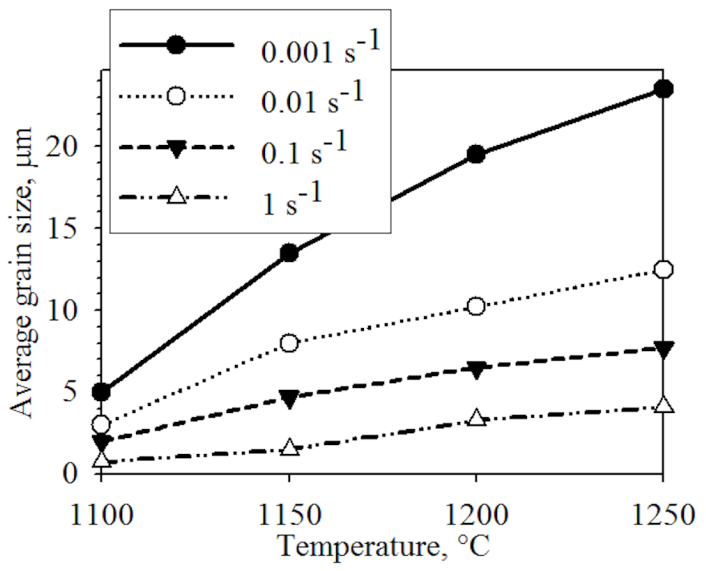

Fig. 4. The size of spheroidized/recrystallized grains in the $\mathrm{Ti}-44 \mathrm{Al}-2 \mathrm{~V}-1 \mathrm{Nb}-1 \mathrm{Zr}-0.2 \mathrm{Gd}-0.2 \mathrm{~B}$ alloy as a function of deformation temperature and strain rate.

The grain size which was obtained during deformation decreased (with an increase of a strain rate) from $19.5 \mu \mathrm{m}$ (at $\left.\dot{\varepsilon}=0.001 \mathrm{~s}^{-1}\right)$ to $3.3 \mu \mathrm{m}\left(\right.$ at $\left.\dot{\varepsilon}=1 \mathrm{~s}^{-1}\right)$ at $T=$ $1200{ }^{\circ} \mathrm{C}$ and from $23.5 \mu \mathrm{m}$ (at $\dot{\varepsilon}=0.001 \mathrm{~s}^{-1}$ ) to $4.1 \mu \mathrm{m}$ (at $\dot{\varepsilon}=1 \mathrm{~s}^{-1}$ ) at $T=1250^{\circ} \mathrm{C}$ (Fig. 4).

Dependences of the fraction of recrystallized grains (i.e. grains with the grain orientation spread, GOS $<1^{\circ}$ ) on deformation temperatures $\left(1100-1250^{\circ} \mathrm{C}\right)$ and strain rates $\left(0.001-1 \mathrm{~s}^{-1}\right)$ are shown in Fig. 5 . In the $\alpha+\gamma$ phase field $\left(T=1150^{\circ} \mathrm{C}\right)$ at a strain rate of $0.001 \mathrm{~s}^{-1}$ the fraction of the recrystallized grains was $\approx 30 \%$ (Fig. 5a). An increase in strain rate resulted in an increase of fraction of grains with the GOS $<1^{\circ}$ to the maximum of $\approx 72 \%$ at $\dot{\varepsilon}=0.1 \mathrm{~s}^{-1}$. At even higher strain rate, a moderate decrease in the recrystallized fraction to $\approx 63 \%$ was found. 

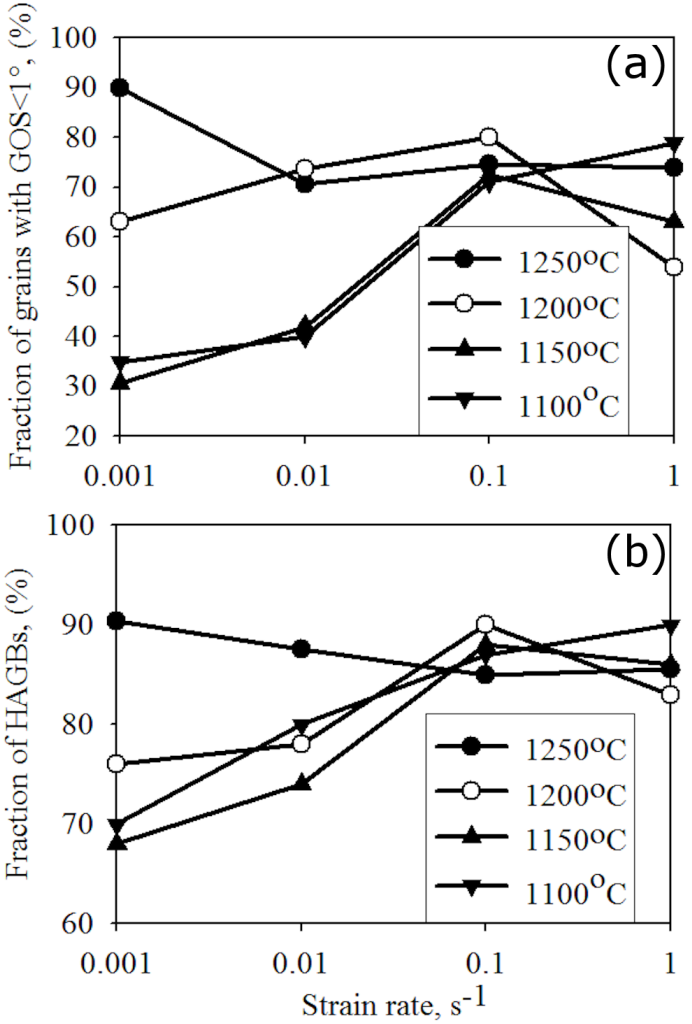

Fig. 5. Dependence of the volume fraction of grains with the GOS $<1^{\circ}$ (a) and the HAGBs fraction (b) calculated from the EBSD data for deformation temperatures of $1150-1250{ }^{\circ} \mathrm{C}$ and strain rates of $0.001-1 \mathrm{~s}^{-1}$.

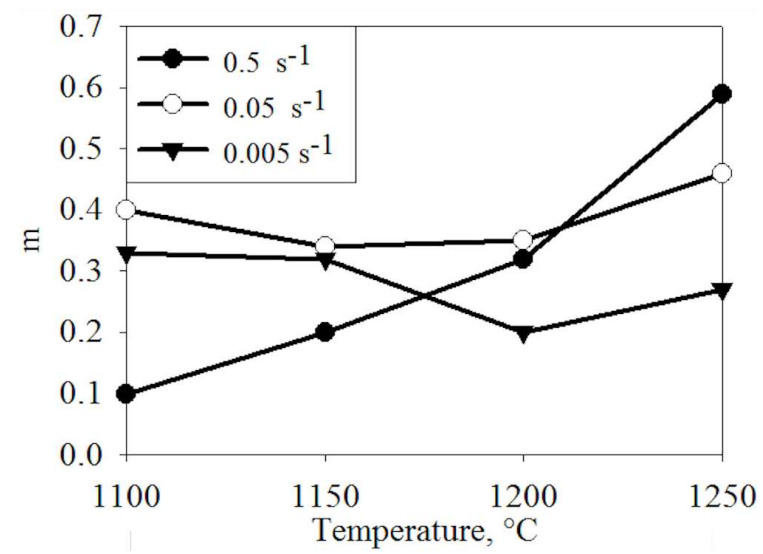

Fig. 6. Dependence of the strain rate sensitivity of flow stress $(m)$ of the $\mathrm{Ti}-44 \mathrm{Al}-2 \mathrm{~V}-1 \mathrm{Nb}-1 \mathrm{Zr}-0.2 \mathrm{Gd}-0.2 \mathrm{~B}$ alloy on deformation temperature and strain rate.

In the $\alpha$ phase field $\left(T=1200^{\circ} \mathrm{C}\right)$ an increase in strain rate also resulted in an increase of the volume fraction of the recrystallized grains (Fig. 5a). The peak value of $\approx 80 \%$ was attained at $\dot{\varepsilon}=0.1 \mathrm{~s}^{-1}$. In the $\alpha+\beta$ phase field $\left(T=1250^{\circ} \mathrm{C}\right)$ the highest fraction of grains with the GOS $<1^{\circ}(90 \%)$ was found at the lowest strain rate of $0.001 \mathrm{~s}^{-1}$. At higher strain rates, the fraction of the recrystallized grains became lower $(70-75 \%)$. This is an indication of diminishing of dynamic recrystallization at high temperatures. In the $\alpha+\gamma$ and $\alpha$ phase fields the $\mathrm{HAB}$ fraction increased with an increase in strain rate and reached the maximum at $0.1 \mathrm{~s}^{-1}$ (Fig. 5b), similarly to the fraction of grains with the GOS $<1^{\circ}$ (Fig. 5a). In the $\alpha+\beta$ phase field $\left(T=1250^{\circ} \mathrm{C}\right)$ the HABs fraction at a strain rate of $0.001 \mathrm{~s}^{-1}$ was $\approx 90 \%$. The HABs fraction slightly reduced with an increase in strain rate.

The strain rate sensitivity of flow stress $(m)$ values was used for the processing maps plotting. The maximum values of $m$ corresponded to the combination of the highest deformation temperatures and the highest strain rates (Fig. 6).

\section{Conclusions}

1. Mechanical behavior of $\mathrm{Ti}-44 \mathrm{Al}-2 \mathrm{~V}-1 \mathrm{Nb}-1 \mathrm{Zr}-$ $0.2 \mathrm{Gd}-0.2 \mathrm{~B}$ alloy in the intervals of temperature from 1100 to $1250{ }^{\circ} \mathrm{C}$ and strain rates from 0.001 to $1 \mathrm{~s}^{-1}$ was investigated. Higher temperatures and lower strain rates were associated with lower flow stress. The shape of the stress-strain curves depended on the deformation temperature. At higher temperature and lower strain rate the duration of a steady plastic flow stage became longer.

2. Microstructure after various deformation conditions was investigated. It was shown that deformation in the studied temperature - strain rates interval in all cases lead to microstructure refinement; the refined microstructure volume increased with an increase in temperature and a decrease in the strain rate.

3. It was shown that superplasticity with the values of the strain rate sensitivity of flow stress $m>0.3$ was observed in all phase fields.

\section{Acknowledgments}

The work was financially supported by Russian Foundation for Basic Research, grant No. 16-08-01061. The authors are grateful to the personnel of the Joint Research Center, "Technology and Materials", Belgorod State National Research University, for their assistance with the instrumental analysis.

\section{References}

[1] F. Appel, J.D.H. Paul, M. Oehring, Gamma Titanium Aluminides Science and Technology, WileyVCH, Weinheim 2011.

[2] H. Clemens, S. Mayer, Adv. Eng. Mater. 15, 191 (2013).

[3] H.Z. Niu, Y.Y. Chen, S.L. Xiao, L.J. Xu, Intermetallics 31, 225 (2012).

[4] G.A. Salishchev, O.N. Senkov, R.M. Imayev, V.M. Imayev, M.R. Shagiev, A.V. Kuznetsov, F. Appel, M. Oehring, O.A. Kaibyshev, F.H. Froes, Adv. Perform. Mater. 6, 107 (1999).

[5] H.Z. Niu, Y.Y. Chen, S.L. Xiao, F.T. Kong, C.J. Zhang, Intermetallics 19, 1767 (2011).

[6] G.A. Salishchev, R.I. Imayev, O.N. Senkov, F.H. Froes, JOM 52, 46 (2000). 